\title{
Autonomic nervous system dysfunction in workers exposed to organic solvents
}

\author{
ESKO MATIKAINEN, JUHANI JUNTUNEN \\ From the Institute of Occupational Health, Helsinki, Finland
}

SUMMARY Tests for cardiovascular function were made in 34 workers exposed to organic solvents for several years (mean 16.2 years). The results were compared with those of 52 healthy subjects. All the cardiovascular parameters were lower in the exposed group. The exposed subjects with evidence of peripheral neuropathy had lower values than those without neuropathy. The findings suggest that peripheral parasympathetic nerves may also be involved in mild sensory-motor peripheral neuropathy among subjects with long-term occupational exposure to organic solvents.

Outbreaks of neurotoxicity in industry have made it clear that long-term high-level exposure to certain solvents can cause disturbances of the nervous system. N-hexane and methyl-butyl-ketone are the only solvents unanimously accepted as a cause of peripheral neuropathy after heavy occupational exposure.' In recent years there have also been reports of slight and more diffuse neurological disorders in workers exposed to solvents other than n-hexane and methyl-butyl-ketone. ${ }^{2-6}$ This clinical syndrome of chronic organic solvent intoxication has received most attention in Scandinavian countries. ${ }^{7}$ Clinical reports indicate that higher mental functions, mood and balance are affected most often, but sometimes the peripheral nervous system also is involved. ${ }^{37}$ The resulting clinical disorder usually is mild and often closely resemble a psychoneurosis.

Disturbances of the autonomic nervous system have been described in many diseases associated with peripheral neuropathy. These include diabetes mellitus, alcoholic neuropathy, uraemia, infectious polyneuropathy, and a few other diseases. ${ }^{89}$ There are no reports of involvement of the autonomic nervous system in cases of solvent intoxication. Typical symptoms of autonomic insufficiency, similar to those seen, for example, in diabetes, are uncommon in patients with solvent intoxication. ${ }^{3}$ However, patients with solvent intoxication often report symptoms of vascular instability, dizziness, palpitations, and impotence, all of which suggest autonomic dis-

Address for reprint requests: Dr E Matikainen, Institute of Occupational Health, Haartmaninkatu 1, SF-00290 Helsinki 29, Finland.

Received 10 April 1984 and in final revised form 1 March 1985. Accepted 8 March 1985 turbance. The present study was undertaken to find out whether workers occupationally exposed to organic solvents showed any evidence of autonomic nervous system disorder.

\section{Patients and methods}

\section{Patients}

The study was of 34 workers, 25 men and 9 women, who had all been referred to the Institute of Occupational Health, Helsinki, Finland, suspected of suffering from occupational solvent intoxication. Their mean age was 45.8 years (range 27-61 years). None of the subjects was receiving any medical treatment, and none had any cardiac, pulmonary, or metabolic diseases. None was known to abuse alcohol.

The control group consisted of 52 healthy volunteers, including staff members and various subjects of other studies. Their mean age was 41.0 years (range 26-61 years).

\section{Exposure data and routine examinations}

All of the patients had been exposed to organic solvents for several years (mean 16.2 years, range $5-30$ years) at their work. Most (28) had been exposed to a mixture of solvents containing mainly aliphatic, aromatic, and other hydrocarbons, alcohols, ketones, esters and ethers. Three people had been exposed only to carbon disulphide and three to toluene (industrial toluene, which also contains considerable amounts of xylene and benzene). In all cases the exposure was initially considered high enough to be able to cause neurological disease. The mean ages of the different exposure groups are presented in table 1 .

All of the participants in the study were fully informed about the procedure and freely gave their informed consent. The patients and the controls were examined neurologically by the authors. All of the exposed subjects also underwent neurophysiological (EEG and ENMG) and psychological examinations as a routine part of the diag- 
Table 1 The mean ages and cardiovascular reflexes $( \pm S D)$ in groups of subjects exposed to different organic solvents.

\begin{tabular}{|c|c|c|c|c|}
\hline $\begin{array}{l}\text { Exposure (number } \\
\text { of subjects) }\end{array}$ & Mean age (years) & $S D(m s)$ & $c \dot{R} R I V \%$ & $V R$ \\
\hline $\begin{array}{l}\text { Controls (52) } \\
\text { Mixed (28) } \\
\text { CS (3) } \\
\text { Toluene (3) } \\
\text { All exposed (34) }\end{array}$ & $\begin{array}{l}41.0 \pm 8.5 \\
45.9 \pm 9.9 \\
51.3 \pm 6.4^{*} \\
39.7 \pm 12.7 \\
45.8 \pm 9.9^{*}\end{array}$ & $\begin{array}{l}47 \cdot 0 \pm 21 \cdot 5 \\
33 \cdot 2 \pm 17 \cdot 4^{*} \\
28 \cdot 9 \pm 16 \cdot 5 \\
44 \cdot 5 \pm 8 \cdot 0 \\
33 \cdot 8 \pm 16 \cdot 7 \dagger\end{array}$ & $\begin{array}{l}5.1 \pm 1.9 \\
3.9 \pm 2.0^{*} \\
3.4 \pm 1.9 \\
5.4 \pm 8.0 \\
3.9 \pm 1.9 \dagger\end{array}$ & $\begin{array}{l}2.05 \pm 0.49 \\
1.95 \pm 0.52 \\
1.64 \pm 0.27 \\
2.28 \pm 0.58 \\
1.95 \pm 0.52\end{array}$ \\
\hline
\end{tabular}

SD = standard deviation of mean R-R-interval. cRRIV = coefficient of variation. VR $=$ Valsalva ratio. CS $_{2}=$ carbon disulphide. Significances compared with controls: ${ }^{*}=p<0.05 . \dagger=p<0.01$.

nostic procedure. ${ }^{7}$ Seventeen of the patients fulfilled the diagnostic criteria for organic solvent intoxication: ${ }^{10}$ (1) verified exposure to organic solvents known to cause neurological disease, (2) objective abnormal findings in neurological examination and in clinical neurophysiological or psychological examinations, (3) other organic diseases excluded, (4) primary psychiatric disorders excluded.

In most cases the main clinical finding was a slight organic brain syndrome, usually associated with EEG abnormalities. Five subjects had clinical and neurophysiological evidence of disturbances of the peripheral nervous system, for example diminished or abolished tendon reflexes and/or diminished sensibility of light touch and pain. Two of these workers had been exposed to carbon disulphide. Seven other subjects had slight abnormalities in either clinical neurological or neurophysiological examinations which, however, did not fulfill the diagnostic criteria for polyneuropathy. ${ }^{21}$ The findings of the examination of the autonomic nervous system were not considered when the diagnosis of the possible organic solvent intoxication was made, and thus they were not a part of the diagnostic process.

\section{Tests for autonomic functions}

The functions of the autonomic nervous system were estimated by measuring the variation in heart rate and the Valsalva ratio. These tests are known to reflect mainly parasympathetic activity" and were chosen because, in most cases of autonomic neuropathy, the parasympathetic system has been shown to be affected first." The variation in heart rate was measured from the ECG recorded with the subject lying and breathing normally, preceded by a 10 minute rest. The variation in heart rate was expressed as the standard deviation of the mean $R-R$ interval and the mean square successive difference, which have been shown to reflect parasympathetic function closely. In all cases 120 successive $\mathbf{R}-\mathbf{R}$ intervals were measured and used in the calculations. Since the variation in heart rate is affected by the heart rate itself, another value, the coefficient of variation of the R-R intervals (cRRIV) was calculated to abolish the effect of the heart rate. cRRIV was calculated as follows: ${ }^{12}$

$$
\text { cRRIV }=\frac{\text { standard deviation } \times 100 \%}{\text { mean } R-R \text { interval }}
$$

The Valsalva ratio ${ }^{13}$ was also used as a parameter. The ratio was defined in routine manner as the ratio between the longest $\mathbf{R}-\mathbf{R}$ interval after and the shortest $\mathbf{R}-\mathbf{R}$ interval during a Valsalva manoeuvre, which was accomplished by asking the patient to blow into a mercury manometer for 15 seconds against $40 \mathrm{mmHg}$ pressure and then to stop blowing immediately. All the ECG recordings were made with ordinary ECG apparatus and the R-R intervals were measured with a digitiser ( $\mathrm{Hi}-\mathrm{Pad}$ ) connected to a micro computer (ABC-80) for processing.

Student's $t$ test, analysis of variance, and chi-square tests were used to calculate the statistical significance of the results.

\section{Results}

All of the values for the cardiovascular reflex parameters were lower among the exposed group than among the controls (table 1). The differences were significant for the values recorded during normal breathing. The distribution of the reflex values in the two groups also differed significantly. Only two controls had SD values below $30 \mathrm{~ms}$ whereas 1 के exposed subjects had SD values lower than $30 \mathrm{~ms}$ None of the controls had a value below $20 \mathrm{~ms}$ whereas six exposed subjects had such a value. similar distribution was seen also for the cRRIK values. These differences were statisticallo significant $(p<0.05)$.

The mean values of autonomic reflex parameters among groups with different exposures are given in table 1 . The patients exposed to carbon disulphide had the lowest values. The patients with mixed exposure also had lower values than the controls, whereas the patients exposed to toluene had normal mean values.

Seventeen subjects with occupational solvent intoxication had lower cardiovascular reflex values than the controls, but owing to the great variability of the figures, the differences were significant only between the SD and the cRRIV values. The mean age of the subjects with a diagnosis of solvent poisoning was higher than that of the controls. The exposed patients without occupational disease had higher values than those with occupational disease, but the differences were not statistically significant.

Nine of the exposed subjects had clinical evidence of disturbances of the peripheral nervous system (diminished reflexes and/or sensory modalities), and eight had decreased conduction velocities, compared with the normal limits of our laboratory. The mean cardiovascular parameters for patients with no peripheral abnormalities (group 1), with either clini- 
Table 2 Variation in heart rate and Valsalva ratio for exposed subjects with no abnormalities in the peripheral nervous system (Group 1), for subjects with abnormalities in either neurological or neurophysiological examinations (Group 2), for subjects with abnormalities in both neurological and neurophysiological examinations (Group 3), and for controls (means $\pm S D)$

\begin{tabular}{|c|c|c|c|c|}
\hline & Mean age (years) & $S D(m s)$ & $c R R I V \%$ & $V R$ \\
\hline $\begin{array}{l}\text { Group } 1(N=22) \\
\text { Group } 2(N=7) \\
\text { Group } 3(N=5) \\
\text { Controls }(N=52) \\
\text { Controls } 45 \text { years }(N=16)\end{array}$ & $\begin{array}{l}44 \cdot 5 \pm 10 \cdot 3 \\
43 \cdot 1 \pm 8 \cdot 7 \\
51 \cdot 8 \pm 10 \cdot 9 \dagger \\
41 \cdot 0 \pm 8 \cdot 5 \\
51 \cdot 1 \pm 4 \cdot 2\end{array}$ & $\begin{array}{l}37 \cdot 6 \pm 18 \cdot 4 \\
32 \cdot 4 \pm 12 \cdot 3^{*} \\
21 \cdot 3 \pm 7 \cdot 1 \dagger \\
47 \cdot 0 \pm 21 \cdot 5 \\
35 \cdot 3 \pm 7 \cdot 3\end{array}$ & $\begin{array}{l}4 \cdot 4 \pm 2 \cdot 0 \\
4 \cdot 0 \pm 1 \cdot 3 \\
2 \cdot 6 \pm 1 \cdot 0 \dagger \\
5 \cdot 1 \pm 1 \cdot 9 \\
4 \cdot 0 \pm 0.9\end{array}$ & $\begin{array}{l}2.00 \pm 0.51 \\
2.06 \pm 0.61 \\
1.69 \pm 0.51 \dagger \\
2.05 \pm 0.49 \\
1.92 \pm 0.41\end{array}$ \\
\hline
\end{tabular}

SD = standard deviation of mean R-R-interval. $c R R I V=$ coefficient of variation. VR = Valsalva ratio. Significances compared with the controls: ${ }^{*}=p<0.05 ; \dagger=p<0.001$.

cal or neurophysiological abnormalities (group 2), with both clinical and neurophysiological abnormalities (group 3), and for the controls (group 4) are presented in table 2 . The values for the autonomic reflex parameters were lower in correlation with the severity of disturbances in the peripheral nervous system. The patients with abnormalities in both neurological and neurophysiological examinations had the lowest mean values. Two of the workers with an exposure to carbon disulphide belonged to group 3 , whereas the third belonged to group 1 . The mean age of group 3 was higher than that of the controls. However, when the results of group 3 were compared with age-matched controls (table 2), the values were still lower in the exposed group. The differences between the parameters reflecting heart rate variation were statistically significant.

\section{Discussion}

The present results indicate that workers with occupational exposure to organic solvents had lower values for cardiovascular parameters that reflect the function of the parasympathetic division of the autonomic nervous system than did the normal healthy controls. The values were lowest among the patients with clear signs of abnormalities in the peripheral nervous system.

An obvious explanation of these results is that exposure to organic solvents causes autonomic as well as sensory-motor neuropathy in some persons. However, several factors must be considered when exposure-response relationships are evaluated. Firstly, the concept of chronic solvent intoxication is unclear and in no way established. ${ }^{14}$ Obviously, clinical inferences drawn from various epidemiological, psychological or neurophysiological studies on solvent toxicity may be erroneous simply because of difficulties in designing a valid study or interpreting the results of various studies. ${ }^{75}$ Secondly, the estimation of the level of exposure is crucial when the causal relationships are assessed in occupational neurology. Most occupational exposures are caused by mixtures of solvents. The individual solvents used may vary from time to time and so may the levels of individual exposure. ${ }^{16}$ This variation makes the estimation of exposure very difficult. Based on the diagnostic principles described in the section on methods, however, 17 of our patients were diagnosed as having chronic solvent poisoning. This conclusion implies that exposure in general had not been particularly heavy, even though in individual cases heavy exposure cannot be excluded. It must be emphasised that no evidence of even occasional exposure was encountered among the controls. Thus the two groups differed from each other with regard to exposure to solvents. Since the results of the cardiovascular reflex studies were not considered when the diagnosis of occupational disease was made, the differences found between the exposed patients and the controls do not represent circular thinking, a pitfall which is often found in the literature.

Thirdly, age is a potential source of error associated with both exposure and illness. ${ }^{17}$ All the parameters measured are known to be age-dependent, with the possible exception of the postural pulse reaction. ${ }^{18}$ When the exposed group was divided into smaller groups on the basis of the quality of exposure and pathological clinical and neurophysiological findings, the subjects with abnormalities tended to be older than the controls. However, when compared with age-matched controls, the exposed subjects still had lower mean values, especially in parameters reflecting heart rate variation at rest. Furthermore, the mean age of the patients with clear findings of peripheral neuropathy and that of the patients with diagnosed solvent poisoning did not differ from each other, but the reflex parameters in the group with peripheral neuropathy were lower. This finding suggests that the autonomic nervous system is involved in peripheral nervous system disorders irrespective of age. This finding is also in accordance with the observed correlation between peripheral and autonomic nervous system abnormalities in other conditions. ${ }^{19}$

It is of interest that exposure to solvent mixtures 
and especially to carbon disulphide was associated with lower cardiovascular reflex values. Peripheral neuropathy has been described in intoxications caused by carbon disulphide ${ }^{20}$ and by a mixture of solvents ${ }^{21}$ but not in occupational toluene poisonings. Since autonomic neuropathy is known to be closely associated with peripheral neuropathy, it is conceivable that this should be the case also in neuropathies due to intoxications. This may well be so among the workers exposed to carbon disulphide. We consider it, however, unlikely that the peripheral neuropathy caused by carbon disulphide alone could be responsible of the correlation between the degree of neuropathy and autonomic dysfunction in the whole group, because peripheral neuropathy was not a consistent finding among the carbon disulphide group. Autonomic neuropathy may lead to increased mortality as has been reported among diabetics; ${ }^{22}$ this may account for the increased cardiac mortality observed earlier among persons exposed to carbon disulphide. ${ }^{23}$

\section{References}

' Allen N. Solvents and other industrial organic compounds. In: Vinken PJ, Bruyn GW, eds. Intoxications of the Nervous System, part I. Amsterdam: NorthHolland, 1979:361-89.

${ }^{2}$ Axelson O, Hane M, Hogstedt C. A case-referent study on neuropsychiatric disorders among workers exposed to solvents. Scand J Work Environ Health 1976; 2:14-20.

${ }^{3}$ Juntunen J, Hupli V, Hernberg S, Luisto M. Neurological picture of organic solvent poisoning in industry. Int Arch Occup Environ Health 1980;46:219-31.

${ }^{4}$ Mikkelsen S. A cohort study of disability pension and death among painters with special regard to disabling presenile dementia as an occupational disease. Scand J Soc Med 1980; Suppl.16.

s Antti-Poika M. Prognosis of patients with diagnosed chronic organic solvent intoxication. Helsinki: Academic dissertation, 1983.

- Arlien-Søborg P. Kronisk toksisk enkefalopati hos hygiensmalere. Copenhagen: Academic dissertation, 1983.

7 Juntunen J. Organic solvent intoxications in occupational neurology. Acta Neurol Scand 1984; Suppl.98;69:105-20.

${ }^{8}$ McLeod JG. Autonomic nervous system. In: Sumner AJ, ed. The Physiology of Peripheral Nerve Disease. Philadelphia: WB Saunders Co, 1980.
"Hilsted J. Autonomic neuropathy: the diagnosis. Acta Neurol Scand 1983;67:193-201.

${ }^{10}$ Juntunen J, Antti-Poika M, Tola S, Partanen T. Clinical prognosis of patients with diagnosed chronic solvent intoxication. Acta Neurol Scand 1982;65:488-503.

"Ewing DJ, Campbell IW, Clarke BF. Assessment of cardiovascular effects in diabetic autonomic neuropathy and prognostic implications. Ann Intern Med 1980;92:308-11.

12 Endre ZH, Perl SI, Kraegen EW, Chaslesworth JA, McDonald GJ. Reduced cardiac beat-to-beat variation in chronic renal failure: a ubiquitous marker of autonomic neuropathy. Clin Sci 1982;5:561-2.

${ }^{13}$ Levin AB. A simple test of cardiac function based upon the heart rate changes induced by the Valsalva maneuver. Am J Cardiol 1966; 18:90-9.

14 Juntunen J. Alcoholism in occupational neurology: diagnostic difficulties with special reference to the neurological syndromes caused by exposure to organic solvents. In: Juntunen J, ed. Occupational Neurology. Acta Neurol Scand Suppl. 92 1982;66:89-108.

${ }^{15}$ Hernberg S. Neurotoxic effects of long-term exposure to organic hydrocarbon solvents. Epidemiologic aspects. In: Holmstedt B, Lauwerys M, Mercier M, Roberfroid M, eds. Mechanisms of Toxicity and Hazard Evaluation. Amsterdam: Elsevier/North-Holland Biomedical Press, 1980:307-17.

16 Järvisalo J, Tossavainen A. Exposure to neurotoxic agents in Finnish working environments. Trends and assessment of exposure. In: Juntunen J, ed. Occupational Neurology. Acta Neurol Scand, Suppl 92 1982;66:37-45.

17 Miettinen OS. Confounding and effect modification. Am J Epidemiol 1974;100:350-3.

${ }^{18}$ Clarke BF, Ewing DJ, Campbell IW. Diabetic autonomic neuropathy. Diabetologia 1979;17:195-212.

14 Thomas PK, Eliasson S. Diabetic neuropathy. In: Dyck PJ, Thomas PK, Lambert E, eds. Peripheral Neuropathy, eds. Philadelphia: WB Saunders Co 1975:956-81.

${ }^{20}$ Seppäläinen AM, Haltia M. Carbon disulphide. In: Spencer PS, Schaumburgh HH, eds. Experimental and Clinical Neurotoxicology. Baltimore, London: Wilkins \& Wilkins 1980:356-73.

${ }^{21}$ Juntunen J, Haltia M. Polyneuropathies in occupational neurology: pathogenetic and clinical aspects. In: Juntunen J, ed. Occupational Neurology. Acta Neurol Scand, Suppl. 92 1982;66:59-73.

${ }^{22}$ Ewing DJ, Campbell IW, Clarke BF. The natural history of diabetic autonomic neuropathy. $Q J$ Med 1980;193:95-108.

${ }^{23}$ Tolonen M. Chronic subclinical carbon disulfide poisoning. Scand J Work Environ Health 1974;11:154-61. 